\title{
Functional Stability of Retinal Ganglion Cells after Degeneration-Induced Changes in Synaptic Input
}

\author{
David J. Margolis, ${ }^{1}$ Gregory Newkirk, ${ }^{1}$ Thomas Euler, ${ }^{2}$ and Peter B. Detwiler ${ }^{1}$ \\ ${ }^{1}$ Department of Physiology and Biophysics and Program in Neurobiology and Behavior, University of Washington, Seattle, Washington 98195, and \\ ${ }^{2}$ Department of Biomedical Optics, Max Planck Institute for Medical Research, 69120 Heidelberg, Germany
}

\begin{abstract}
Glutamate released from photoreceptors controls the activity and output of parallel pathways in the retina. When photoreceptors die because of degenerative diseases, surviving retinal networks are left without their major source of input, but little is known about how photoreceptor loss affects ongoing synaptic activity and retinal output. Here, we use patch-clamp recording and two-photon microscopy to investigate morphological and physiological properties of identified types of ON and OFF retinal ganglion cells (RGCs) in the adult (36-210 d old) retinal degeneration $r d-1 / r d-1$ mouse. We find that strong rhythmic synaptic input drives ongoing oscillatory spike activity in both ON and OFF RGCs at a fundamental "beating" frequency of $\sim 10 \mathrm{~Hz}$. Despite this aberrant activity, ON and OFF cells maintain their characteristic dendritic stratification, intrinsic firing properties, including rebound firing in OFF cells, balance of synaptic excitation and inhibition, and dendritic calcium signaling. Thus, RGCs are inherently stable during degeneration-induced retinal activity.
\end{abstract}

Key words: retinal degeneration; photoreceptor; blindness; ganglion cells; dendrites; calcium

\section{Introduction}

The vertebrate retina is an image processor. Visual information is detected by rod and cone photoreceptors, filtered through parallel synaptic pathways, encoded in action potentials by 12-15 different types of retinal ganglion cells (RGCs), and sent to the brain via the optic nerve (Masland, 2001; Wassle, 2004; Field and Chichilnisky, 2007). Synaptic output signals from photoreceptors initiate this sequence of events by controlling the activity of downstream retinal circuits. Permanent loss of photoreceptors, as occurs in many types of degenerative diseases (Phelan and Bok, 2000; Daiger et al., 2007), would be expected to have dramatic functional consequences, but alterations in the physiology of surviving retinal circuitry have not been specified.

In the retinal degeneration $r d-1 / r d-1$ (RD) mouse, rod and cone photoreceptors progressively die in the first weeks after birth, leading eventually to the severe changes in cellular architecture and remodeled neural circuitry that characterize retinal degeneration (Blanks et al., 1974; Carter-Dawson et al., 1978; Jimenez et al., 1996; Strettoi and Pignatelli, 2000; Marc et al., 2003; Punzo and Cepko, 2007). Little is known about the functional adaptations that accompany these morphological changes. Recent studies in the RD mouse indicate that, surprisingly, pho-

\footnotetext{
Received Sept. 18, 2007; revised May 14, 2008; accepted May 14, 2008.

This work was supported by National Institutes of Health Grants EY02048 (P.B.D.), GM07108 (D.J.M.), and EY01730-31 (Vision Research Center), Human Frontiers Science Program Grant RGP-0067 (G.N.), and the Max Planck Society (T.E.). We thank W. Denk for design and construction of the two-photon microscope and continued support and advice, F. Dunn, I. Fine, A. Horsager, and F. Rieke for helpful discussion, D. Possin for histology, and P. Newman for technical assistance.

Correspondence should be addressed to either of the following: Peter B. Detwiler, Department of Physiology and Biophysics, University of Washington, Box 357290, Seattle, WA 98195, E-mail: detwiler@u.washington.edu; or David J. Margolis at his present address, Department of Neurophysiology, Brain Research Institute, University of Zurich, CH-8057 Zurich, Switzerland, E-mail: margolis@hifo.uzh.ch.

DOI:10.1523/JNEUROSCI.1533-08.2008

Copyright $\odot 2008$ Society for Neuroscience $\quad 0270-6474 / 08 / 286526-11 \$ 15.00 / 0$
}

toreceptor loss results in increased rather than decreased retinal activity (Marc et al., 2007; Stasheff, 2008). Excitation mapping of organic cations showed increased glutamate drive [postnatal day 60 (P60)-P90] (Marc et al., 2007), and multielectrode array recordings indicated that RGC spike rate has also increased (P7P115) (Stasheff, 2008). But how the functional properties of RGCs change after photoreceptor loss, including presynaptic and postsynaptic mechanisms, is not understood. This information is critical for retina-based vision rescue strategies, which depend on functional stability of RGCs and their underlying synaptic circuits.

Previous work on three functional types of "large soma" RGCs in wild-type (WT) mouse retina [ON, OFF transient (OFF-T), and OFF sustained (OFF-S)] found distinguishing differences in their dendritic morphology, synaptic input, and intrinsic physiological properties (Pang et al., 2003; Murphy and Rieke, 2006; Margolis and Detwiler, 2007). These cells are excited by either light increments (ON cells) or decrements (OFF cells) and represent the output of two fundamental parallel pathways (Schiller, 1992). Their dendritic arbors stratify at different depths within the inner plexiform layer (IPL), and they exhibit characteristic intrinsic electrical properties, including the ability of OFF cells to fire "rebound" bursts after hyperpolarization (Margolis and Detwiler, 2007).

Here, we take advantage of these distinctive differences to identify ON and OFF type RGCs in the blind RD retina and investigate the effect of photoreceptor loss on their morphologi$\mathrm{cal}$, electrophysiological and $\mathrm{Ca}^{2+}$ signaling properties using a combination of patch-clamp recordings and two-photon laserscanning fluorescence microscopy. We find that strong rhythmic synaptic input drives oscillatory spike activity in both $\mathrm{ON}$ and OFF RGCs at P36-P50, when virtually all photoreceptors are lost. Intrinsic properties of RGCs, however, are maintained, even into 
late-stage retinal degeneration (P210). These results reveal a high degree of functional stability in RGCs, despite dramatic degeneration-induced changes in synaptic activity.

\section{Materials and Methods}

Animals. Experimental procedures were similar to those in previous work (Margolis and Detwiler, 2007). All experiments were done in accordance with local and national guidelines for animal care. Unless noted otherwise adult C3HeJ mice $(r d-1 / r d-1)$ were used at P36-P50 (P44 \pm 4 , mean $\pm \mathrm{SD} ; n=12$ ), when their retinas were not responsive to light because of the loss of photoreceptors. Experiments were also done on RGCs from P124, P158, and P210 RD retina (one mouse at each age). These ages represent later stages in the degenerative disease and show evidence of more advanced changes in retina structures (Jones et al., 2003, 2005; Marc and Jones, 2003; Marc et al., 2003, 2007). In this, as in other studies (Pang et al., 2003; Murphy and Rieke, 2006; Sagdullaev et al., 2006; Margolis and Detwiler, 2007), information about WT (C57BL/6) RGCs was obtained from adult (P28-P56) animals and used for controls as indicated in the figures. Both WT and RD mice were obtained from The Jackson Laboratory. Animals were housed in temperature-regulated facilities on a $12 \mathrm{~h}$ light/dark cycle and had ad libitum access to food and water. Neither WT nor RD mice were dark adapted for these experiments.

Tissue preparation. Retinas from WT and RD mice were treated identically. Mice were killed by cervical dislocation. Their eyes were removed, bathed in room temperature-oxygenated (gassed with $95 \% \mathrm{O}_{2}$ and $5 \%$ $\mathrm{CO}_{2}$ ) Ames medium (Sigma), hemisected, and the cornea and lens were removed. The resulting eyecup was cut into two to four pieces, and the retina was isolated by gently teasing it from the pigment epithelium. Extra pieces/eyecups were stored in oxygenated Ames until needed. The vitreous was removed from the retina with forceps before mounting it flat, photoreceptor-side down, on Anodisc filter paper (Whatman) that was mechanically fixed to the glass bottom of a recording chamber, mounted on the stage of a two-photon fluorescence microscope (see below), and superfused with warmed $\left(30-34^{\circ} \mathrm{C}\right)$, oxygenated Ames at a rate of $4-8 \mathrm{ml} / \mathrm{min}$.

Cell identification. The flat-mount retina was viewed on a video monitor using infrared illumination and a CCD camera. WT RGCs were identified as ON, OFF transient, or OFF sustained based on physiological and morphological criteria, as in previous work (Margolis and Detwiler, 2007). Light responses from WT cells could often be used for cell identification even under light adapted conditions. In the presence of synaptic blockers for WT, and in all cases for RD retinas, cell types were identified based on their morphology using differences in the retinal location of their dendritic arbors. The depth of dendritic stratification in the IPL was measured as described in a previous study (Margolis and Detwiler, 2007). Briefly, at the end of patch recording, green fluorescence from an RGC filled with a $\mathrm{Ca}^{2+}$ indicator (see below) was measured using $Z$-series image stacks and compared with red fluorescence acquired simultaneously from bath-applied sulforhodamine-101 (SR-101). In an SR-101stained $Z$-series image stack, the inner and outer boarders of the IPL borders were defined (starting at the ganglion cell layer) as the first and last image to contain no somata, respectively. Dendritic stratification was expressed as the location of the peak dendritic fluorescence within the IPL borders.

Histology. For gross morphological comparison, WT and RD retinas were fixed in PIPES-buffered $2.5 \%$ glutaraldehyde/1.6\% paraformaldehyde, dehydrated, plastic-embedded, and stained with $10 \%$ Richardson's stain. Cross sections $(5 \mu \mathrm{m})$ from midperipheral retina were photographed using a $40 \times 1.3$ numerical aperture (NA) oil objective and standard light microscopy. Shrinkage caused by fixation/dehydration was not corrected for.

Electrical recordings. Cells in the ganglion cell layer with large diameter $(18-25 \mu \mathrm{m})$ somas were targeted for patch-clamp recordings in the flatmount retina. Electrode access to a selected cell was obtained by using an empty patch pipette to microdissect the internal limiting membrane above it (Taylor et al., 2000; Murphy and Rieke, 2006; Margolis and Detwiler, 2007). Patch-clamp recordings were made using 3-7 M $\Omega$ elec- trodes, and signals were amplified using either Axopatch 200B or Axoclamp 2B amplifiers. For whole-cell recordings, unless noted otherwise, the standard internal solution contained (in $\mathrm{mm}$ ) $120 \mathrm{~K}$-gluconate, 5 $\mathrm{NaCl}, 5 \mathrm{KCl}, 5 \mathrm{HEPES}, 1 \mathrm{MgCl}_{2}, 1$ adenosine 5'-triphosphate, and 0.1 guanosine $5^{\prime}$-triphosphate, adjusted to $\mathrm{pH} 7.4$ with $\mathrm{KOH}$, plus $125-140$ $\mu \mathrm{M}$ Oregon Green BAPTA-1 (OGB-1) or $250 \mu \mathrm{M}$ Fluo-5F for $\mathrm{Ca}^{2+} \mathrm{im}_{-}$ aging (Invitrogen). In experiments involving ratiometric fluorescence measurements, the internal solution also included $100 \mu \mathrm{M}$ Alexa-594, a $\mathrm{Ca}^{2+}$ insensitive dye. In experiments to isolate inhibitory and excitatory currents the voltage-clamp internal solution contained (in mM) 105 Cs$\mathrm{MeSO}_{4}, 10$ tetraethylammonium $\mathrm{Cl}, 20$ HEPES, lidocaine $N$-ethyl bromide, 5 ATP-Mg, and 0.5 GTP-Tris, plus $125-140 \mu \mathrm{M}$ OGB- 1 or $250 \mu \mathrm{M}$ Fluo-5F. Corrections for a $10 \mathrm{mV}$ liquid junction potential were done off-line. To isolate cells from synaptic inputs, we used a mixture of bathapplied synaptic antagonists (in $\mu \mathrm{M}$ ): $20 \mathrm{CNQX}, 50 \mathrm{APV}, 1$ strychnine, 50 picrotoxin, and 50 L-APB [a metabotropic glutamate receptor 6 (mGluR6) agonist]. Current and voltage stimuli were generated and data acquired through an ITC-16 interface (Instratech) using software written in Igor Pro (Wavemetrics) by Fred Rieke (University of Washington, Seattle, WA). All chemicals were purchased from Sigma or Tocris.

Optical recordings. Fluorescence measurements were made using a custom built two-photon laser-scanning microscope (Denk et al., 1990; Euler et al., 2002; Margolis and Detwiler, 2007), designed around Sutter micromanipulators (Sutter Instrument) and controlled by CfNT software (written by Ray Stepnoski, Bell Laboratories, Murray Hill, NJ; and Michael Muller, Max-Planck-Institute for Medical Research, Heidelberg, Germany). Fluorescence excitation was provided by a pumped infrared laser (Mira; Coherent) at $905-930 \mathrm{~nm}$, and collected by a $60 \times 1.0 \mathrm{NA}$ water-immersion objective (Nikon). Custom bandpass (BP) filters (Chroma Technology) directed green (535 BP $50 \mathrm{~nm}$ ) and red (622 BP 36 $\mathrm{nm})$ fluorescence to two independent photomultiplier tubes (Hamamatsu). The green channel was used for $\mathrm{Ca}^{2+}$ indicator fluorescence, and the red channel was used for either bath-applied SR-101 or intracellularly applied Alexa-594.

Data analysis. Electrophysiological data were analyzed in Igor Pro, which was also used to analyze optical data along with ImageJ (http:// rsb.info.nih.gov/ij/). To measure the frequency characteristics of electrical activity, power spectral density functions (PSDs) were computed from long $(>15 \mathrm{~s})$ current or voltage sweeps using built-in routines in Igor that measured power in $1.22 \mathrm{~Hz}$ bins. The fundamental "beating" frequency was measured as the peak power in the range $3-20 \mathrm{~Hz}$, determined by Gaussian fit to PSDs. Fits were used to obtain a more accurate estimation than allowed by the $1.22 \mathrm{~Hz}$ binning. PSDs were computed from either cell-attached spiking, whole-cell current-clamp recordings of subthreshold and superthreshold voltage, or whole-cell voltage-clamp recordings of synaptic currents. Clear peaks were evident from all of these types of recordings and rhythmicity could be confirmed in raw traces by visual inspection. Beating frequencies as measured from current- and voltage-clamp recordings were combined for group averages (see Table 1) because they were not different when measured using either type of recording. Correlation (see Figs. 4, 5) was measured with the Pearson test.

To relate properties of calcium signaling and evoked spike firing (see Fig. 7), we chose a simple index of $\Delta F / F$ per spike, expressed as the percentage $\mathrm{Ca}^{2+}$ change (after background subtraction) per action potential. For responses to depolarizing stimuli, $\Delta F / F$ per spike was measured from responses in the middle (linear) range of a cell's spike frequency-current intensity relationship. For rebound firing, $\Delta F / F$ per spike was calculated from strong responses usually comprised of two to four spikes.

\section{Results}

\section{Identification of ganglion cell types in $\mathrm{RD}$ retina}

In the RD mouse, the vast majority of photoreceptors die within 2-3 weeks of age and outer retina morphology is severely altered (Blanks et al., 1974; Carter-Dawson et al., 1978; Farber et al., 1994; Jimenez et al., 1996; Punzo and Cepko, 2007). By P40, photoreceptor outer segments as well as the outer nuclear layer 
A
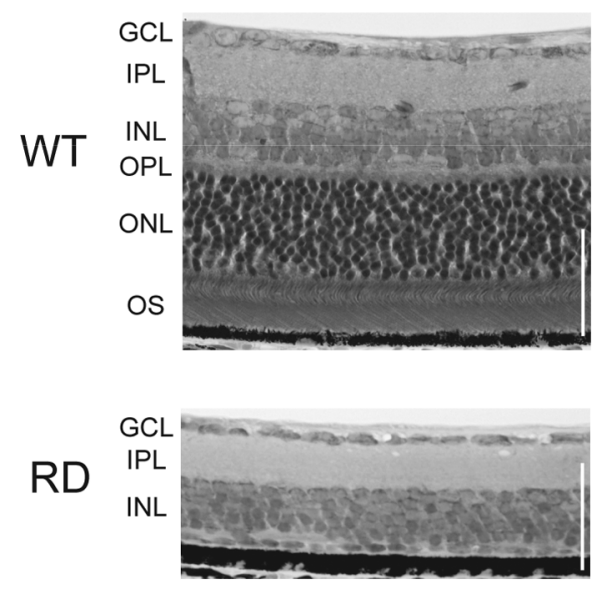

$\mathrm{B}$
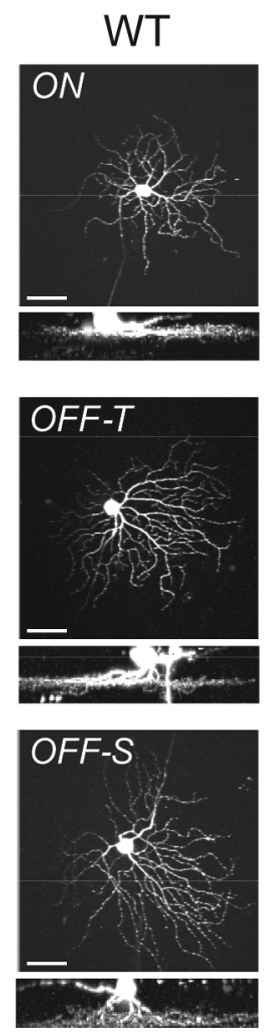
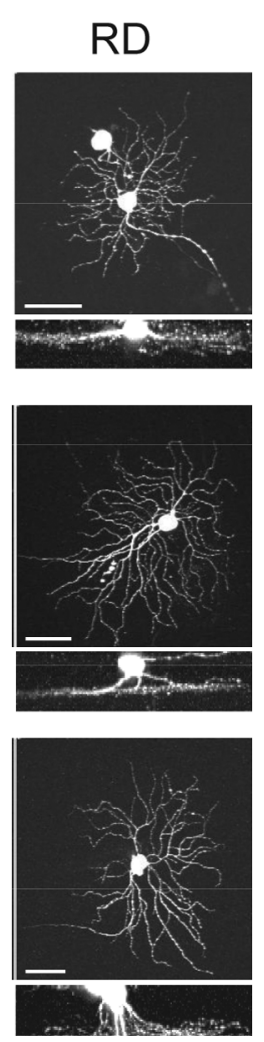

C
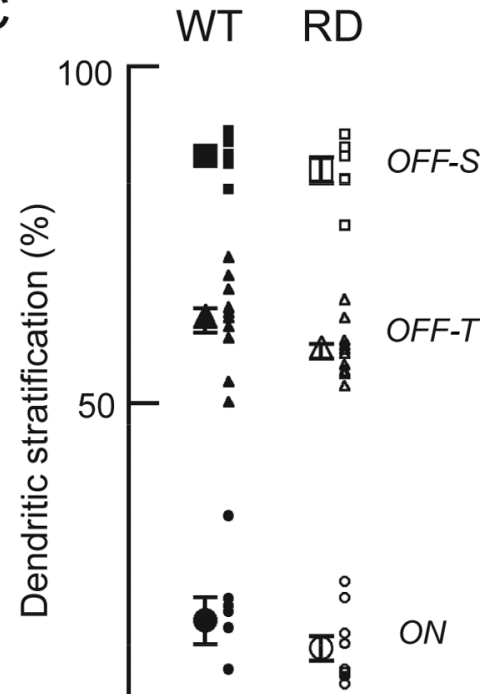

Figure 1. Identification of three RGC types in adult RD retina (mean age $\pm S D, P 44 \pm 4$ ). $A$, Cross sections of fixed tissue show gross structural differences of WT and RD retinas. Note the lack of outer plexiform layer (OPL), outer nuclear layer (ONL), and photoreceptor outer segments (OS) in RD retina. GCL, Ganglion cell layer; INL, inner nuclear layer. $\boldsymbol{B}$, Two-photon z-projections (larger top images) and side projections (below) of three identified types of WT (left) and RD (right) RGCs. Cells were filled with $125 \mu \mathrm{m}$ OGB-1 during patch-clamp recordings. C, Dendritic stratification within the IPL for populations of ON ( $n=7$ WT, 9 RD), OFF-T ( $n=12$ WT, 12 RD), and OFF-S ( $n=5$ WT, 6 RD) RGCs from WT (filled symbols) and RD (open symbols) retina. See Results for statistical comparisons. The WT data in C is from Margolis and Detwiler (2007). Scale bars, $50 \mu \mathrm{m}$. Error bars indicate SEM.

and outer plexiform layer have been mostly eliminated (Fig. $1 A$ ). In contrast, inner retina structures appear intact, including the inner nuclear layer, IPL, and ganglion cell layer at this age and older (P196 and P226) (supplemental Fig. 3, available at www. jneurosci.org as supplemental material). This is consistent with descriptions in numerous previous studies (Strettoi and Pignatelli, 2000; Strettoi et al., 2002; Jones et al., 2003; Marc and Jones, 2003; Marc et al., 2003) and shows that RGCs survive after photoreceptor loss and subsequent degenerative changes in the retina (Jones and Marc, 2005; Daiger et al., 2007).

In adult WT mouse retina, three types of ON and OFF ganglion cells (ON, OFF transient and OFF sustained) have been identified and can be reproducibly targeted for recording based on their large-diameter (18-25 $\mu \mathrm{m}$ ) cell bodies (Pang et al., 2003; Murphy and Rieke, 2006; Margolis and Detwiler, 2007). These cells are typically classified based on their functional responses to visual stimuli, e.g., ON (excited at light onset) or OFF (excited at light offset), but this is not possible in adult $\mathrm{RD}$ retina because photoreceptors have degenerated and light responses are abolished by $\sim$ P25 (Stasheff, 2008). However, ON and OFF RGCs also have known differences in dendritic structure, notably their stratification depth within the IPL (Nelson et al., 1978). In WT retina, ON, OFF-transient, and OFF-sustained cells can be identified based on this criteria (Margolis and Detwiler, 2007). We hypothesized that dendritic stratification depth might still enable identification of these cell types in the blind $\mathrm{RD}$ retina.

In a flat-mount preparation of $\mathrm{RD}$ retina, cells in the ganglion cell layer with the largest soma diameters $(18-25 \mu \mathrm{m})$ were targeted for whole-cell recording, filled with fluorescent $\mathrm{Ca}^{2+}$ indi- cator (OGB-1 or Fluo-5F), and imaged using two-photon fluorescence microscopy (Fig. $1 B$ ). The branching pattern and size of dendritic arbors of these cells appeared similar to WT cells. Measurement of dendritic stratification showed three clusters at different depths in the IPL (Fig. 1C). Data from 27 identified ON, OFF-T, and OFF-S RGCs in RD retina are compared with WT in Figure $1 C$. As in WT retina, RD cells stratified in three distinct levels of the IPL (ON, $13.7 \pm 1.8 \%$; OFF-T, $57.7 \pm 1.0 \%$; OFF-S, $84.6 \pm 1.9 \% ; p \ll 0.001$ for ON-OFF-T and OFF-T-OFF-S). Stratification depths were not statistically different from WT [data are from the study by Margolis and Detwiler (2007)] in any of the three groups (ON: $p=0.33$; RD, $n=9$; WT, $n=7$; OFF-T: $p=0.06$; RD, $n=12$; WT, $n=12$; OFF-S: $p=0.41$; RD, $n=6$; WT, $n=5$ ).

Because the differences in the stratification depth of the dendrites of RGCs in the RD retina corresponded to the differences in the dendritic depths of ON, OFF-S and OFF-T RGCs in the lightsensitive WT retina, they were used to identify these cell types in the light-insensitive RD retina. Experiments described in later sections further validate this classification scheme by demonstrating that the different morphological classes of RD cells exhibit the same distinguishing intrinsic electrical and dendritic $\mathrm{Ca}^{2+}$ signaling properties as the three functional cell types in the WT retina. Based on these criteria, RGCs in the RD retina will be referred to henceforth as either ON, OFF-S, or OFF-T.

RGCs in retinas from adult RD mice ranging in age from P36-P210 were studied using a combination of electrical and optical recording. The retinas from older animals $(>$ P50) were thin and fragile making it difficult to isolate an acceptably intact 

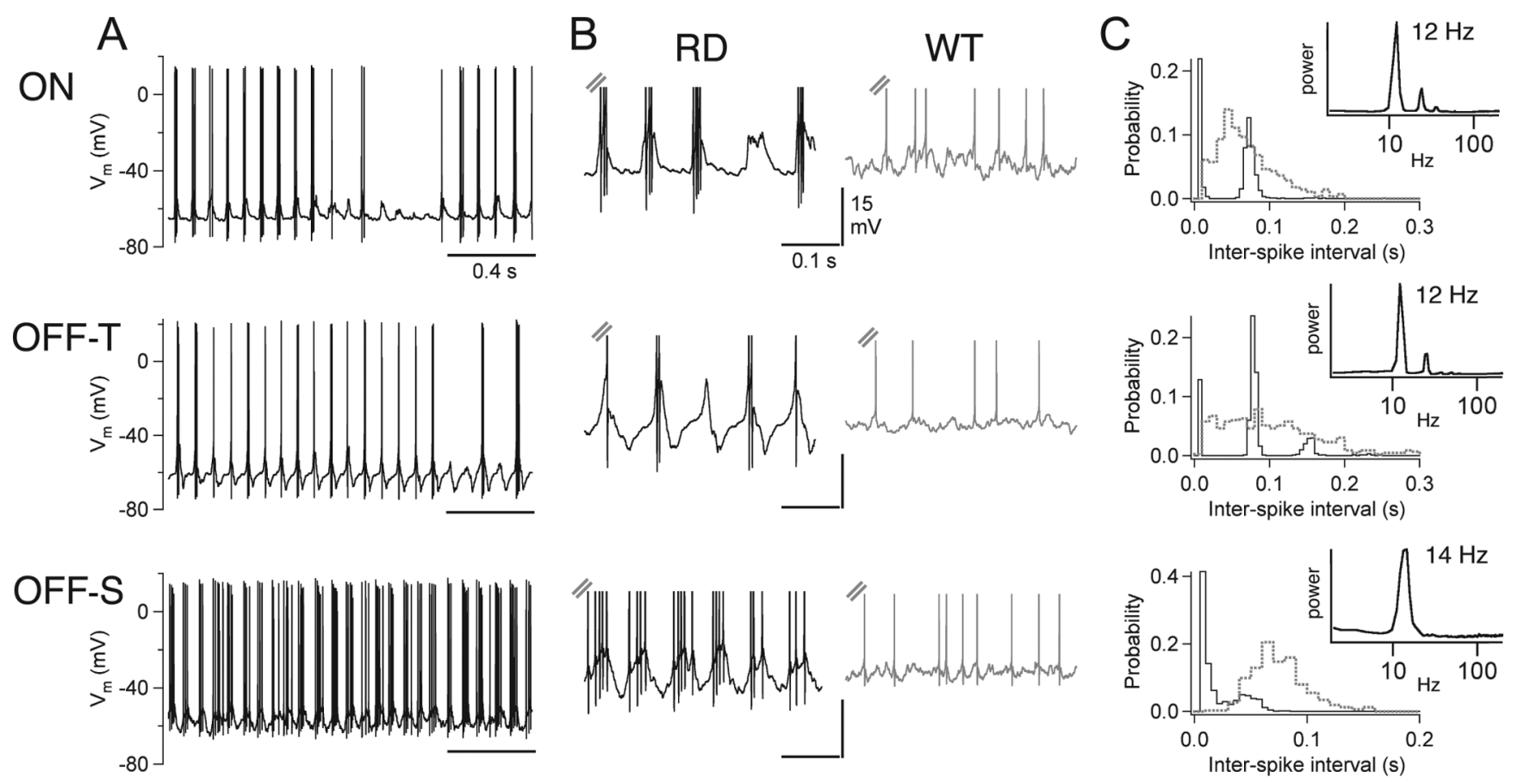

Figure 2. Rhythmic resting spike activity in identified RD RGCS. A, Whole-cell current-clamp recordings from ON, OFF-T, and OFF-S RGCs in RD retina. $B$, Activity on an expanded time scale. Note the underlying oscillatory membrane depolarizations present in RD (left, black) but not WT (right, gray) cells. C, Interspike interval histograms from cells in $\boldsymbol{B}$. Solid line, RD; dotted line, WT. Insets show the power spectra for RD RGCs (same cells as in $\boldsymbol{B}$ ). Note the clear presence of peak frequencies at 12-14 Hz in these cells.

Table 1. Properties of resting spiking and synaptic currents in identified ganglion cell types in RD retina

\begin{tabular}{lllll}
\hline & Spike rate $(\mathrm{Hz})$ & CV of ISI & Fund. freq. (Hz) & Peak EPSC (pA) \\
\hline ON & $22.0 \pm 4.6(11)$ & $1.2 \pm 0.1(11)$ & $9.2 \pm 0.7(13)$ & $-294 \pm 53(11)$ \\
OFF-T & $25.1 \pm 6.6(10)$ & $1.1 \pm 0.2(10)$ & $8.9 \pm 0.8(15)$ & $-189 \pm 42(10)$ \\
OFF-S & $32.7 \pm 7.0(4)$ & $1.1 \pm 0.1(4)$ & $8.5 \pm 1.0(7)$ & $-137 \pm 34(5)$ \\
\hline
\end{tabular}

Data are shown as mean \pm SEM. The number of cells $(n)$ is shown in parentheses. ISI, Interspike interval; Fund. freq., fundamental frequency. $V_{\text {hold }}=-70$ $\mathrm{mV}$.

retina for whole mount recordings. Thus the majority of studies were done on P36-P50 animals, with experiments to evaluate the physiological properties of RGCs on small numbers older RD animals.

\section{Rhythmic resting spike activity in RD RGCs}

In normal (WT) RGCs, the resting spike activity in the absence of light is irregular with little underlying temporal structure (Pang et al., 2003; Murphy and Rieke, 2006; Sagdullaev et al., 2006; Margolis and Detwiler, 2007). In contrast, in RD mice, ON, OFF-T, and OFF-S RGCs displayed striking and consistent patterns of rhythmic resting spike activity (Fig. 2). All three cell types showed continuous rhythmic bursts of spikes with an interburst beating frequency of $\sim 10 \mathrm{~Hz}$ (Fig. $2 \mathrm{~A}$ ). Examination of subthreshold membrane potential revealed oscillatory depolarizations at the same frequency, each crested by $0-5$ spikes (Fig. $2 B$, left). Such activity patterns were not observed in any recordings from WT cells of the same type (Fig. $2 B$, right). Histograms of interspike interval showed groups corresponding to the fundamental beating frequencies $(\sim 12 \mathrm{~Hz} / 0.08 \mathrm{~s}$ interval in these example cells), as well as the higher-frequency spike bursts (Fig. $2 C)$. Spectral analysis revealed clear peaks in power corresponding to the beating frequencies (Fig. $2 C$, insets). The mean beating frequency in all recorded cells $(\mathrm{P} 36-\mathrm{P} 50)$ was $9.0 \pm 0.4 \mathrm{~Hz}(n=$ 35 total; 13 ON, 15 OFF-T, 7 OFF-S; range, 3-14 Hz). There were no differences in beating frequencies between $\mathrm{ON}$ and OFF cell types $(p>0.2)$ (Table 1$)$. The beating frequency of any given cell was the same as measured in either current or voltage clamp (see Fig. 4); therefore, data from both types of recording was pooled for calculation of group means. The overall resting mean spike rate (including spikes that occur in bursts during rhythmic firing) was $24.9 \pm 3.5 \mathrm{~Hz}(n=25$ total; $11 \mathrm{ON}, 10$ OFF-T, 4 OFF-S; range, 5-80 Hz). This is, on average, about twice the mean spike rate of WT cells (Margolis and Detwiler, 2007; Stasheff, 2008). It is also 2.5 -fold higher than the beating frequency, which reflects the fact that rhythmic synaptic input typically generated more than a single spike (see Fig. 4). The high $(>1)$ coefficients of variation $(\mathrm{CV}=\mathrm{SD} /$ mean $)$ are another consequence of the rhythmic nature of firing. These measures are summarized in Table 1. Persistent rhythmic spike activity was present in every recording from identified ON, OFF-T, and OFF-S RGCs in the P36-P50 age group as well as in cells from animals as old as P210, albeit at a slower rate. In older animals both the fundamental beating frequency and mean spike rate were reduced twofold to threefold (supplemental Fig. 3, available at www.jneurosci.org as supplemental material). Maintained rhythmic spike activity is a characteristic feature of RGCs in RD retina that is not seen in WT RGCs. It was present in whole-cell and cell-attached (loose patch) extracellular recordings regardless of the time of day or length of the experiment. These results indicate that the retina continues to generate output signals in both the early and later stages of degeneration-induced loss of photoreceptors.

\section{Oscillatory synaptic input underlies altered resting activity}

The aberrant activity that gives rise to rhythmic spiking in $\mathrm{RD}$ RGCs could be generated either intrinsically, by voltagedependent conductances that give rise to pacemaker currents, or 

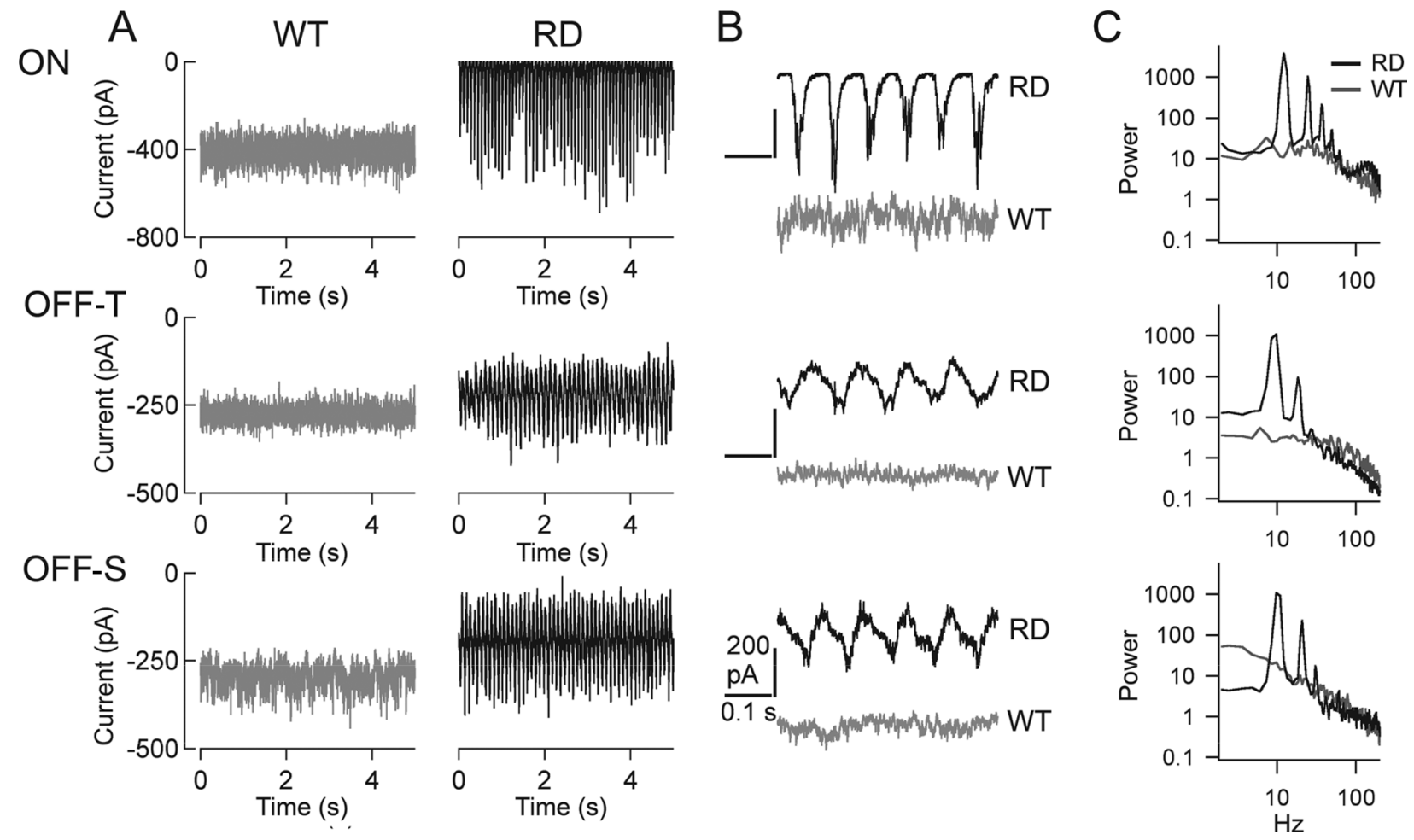

Figure 3. Rhythmic resting synaptic currents in identified RD RGCS. A, Whole-cell voltage-clamp recordings of resting synaptic currents in ON, OFF-T, and OFF-S RGCs from WT (left, gray) and RD (right, black) retinas $\left(V_{\text {hold }}=-70 \mathrm{mV}\right.$ ). B, Currents on an expanded time scale. Note the strong periodicity in $\mathrm{RD}$ currents from all three cell types and different dynamics of currents in $0 \mathrm{~N}$ and $0 \mathrm{FF}$ cells. C, Power spectra of RD (black) and WT (gray) currents (the same cells as in $\boldsymbol{B}$ ). The multiple peaks in RD spectra reflect harmonics of the fundamental beating frequency of $\sim 10 \mathrm{~Hz}$.
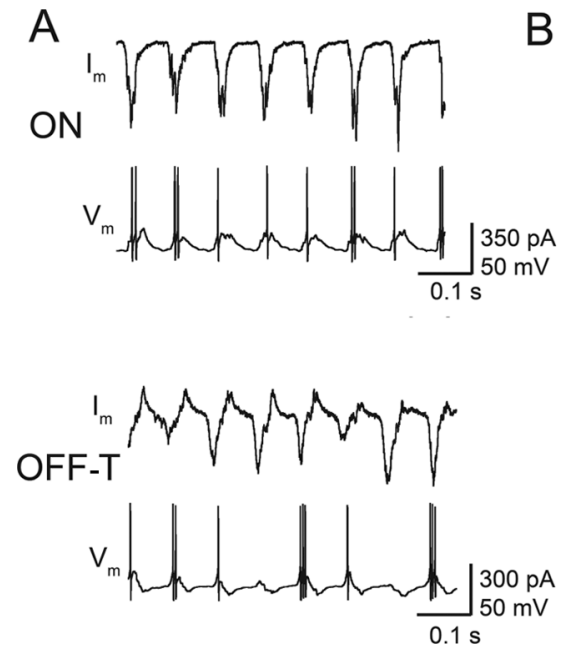

$B$
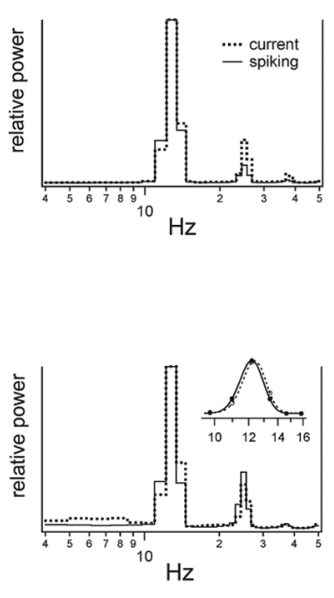

C

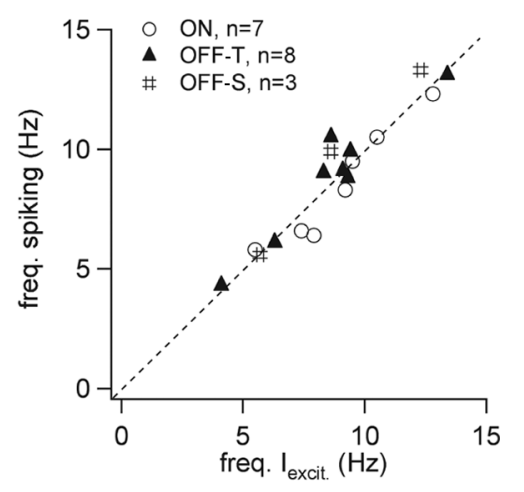

Figure 4. Correlation between spiking and synaptic currents in individual RD RGCs. $A$, Whole-cell voltage-clamp (top; $V_{\text {hold }}=-70 \mathrm{mV}$ ) and current-clamp (bottom) recordings from individual ON (above) and OFF-T (below) cells. B, Power spectra of current (dotted line) and voltage (solid line) from the cells in $\boldsymbol{A}$. The inset shows Gaussian fits to spectra in the range of $3-20 \mathrm{~Hz}$. $\boldsymbol{C}$, Correlation of peak frequencies of spiking and synaptic currents in individual cells $(n=18)$, as measured from power spectra.

extrinsically, by reverberant synaptic input. To test the possibility that synaptic mechanisms are the source of rhythmic activity, RGC membrane potential was held at $-70 \mathrm{mV}$ in whole-cell voltage clamp and resting input currents were measured. Under these conditions, the recorded current showed ongoing clear-cut amplitude fluctuations in ON, OFF-T, and OFF-S cells (Fig. 3) at about the same frequency as rhythmic spiking activity (Fig. 2). Baseline currents of this nature were only seen in RGCs from RD retina: membrane current recorded under the same conditions from WT cells was dominated by low-amplitude baseline synaptic noise with few resolvable discreet events (Fig. 3B). Power spec- tra of $\mathrm{RD}$ current recordings revealed peaks at $\sim 10 \mathrm{~Hz}$ that were not present in WT recordings (Fig. $3 C$ ) and generally matched the frequency of spike activity in current-clamp recordings from RD RGCs (Fig. 2). The correspondence between rhythmic variation in current and voltage (spiking) was examined explicitly by comparing sequential voltage- and current-clamp recordings from the same cells. The traces in Figure $4 A$ illustrate the temporal coincidence between peak inward currents and peak depolarizations that evoked spike bursts in an ON and OFF RD RGC. Spectral analysis of these records reinforces this point by showing that power peaks at the same frequency in voltage and current 

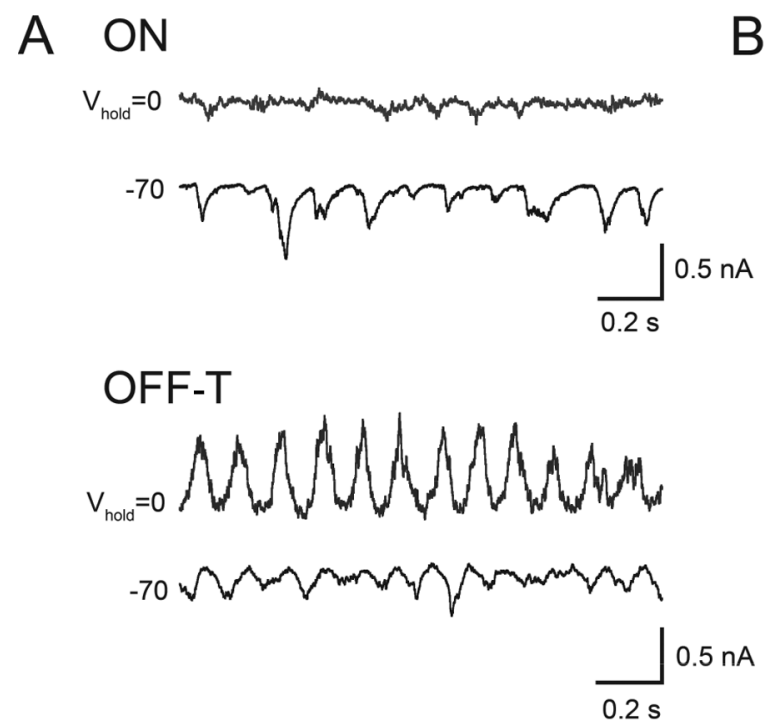

OFF-S

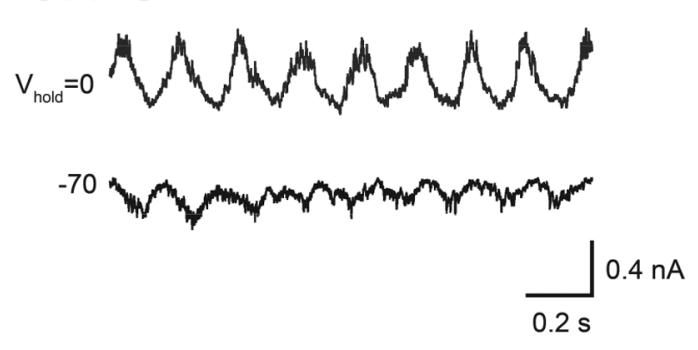

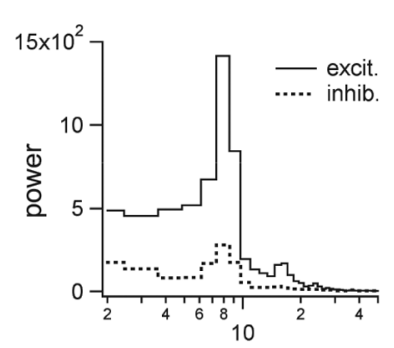
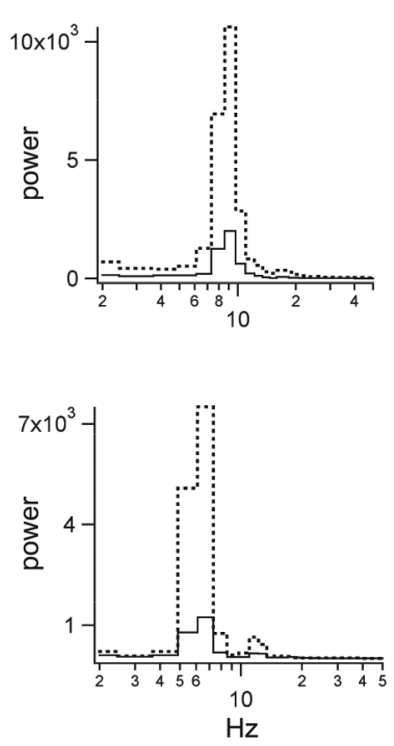

C
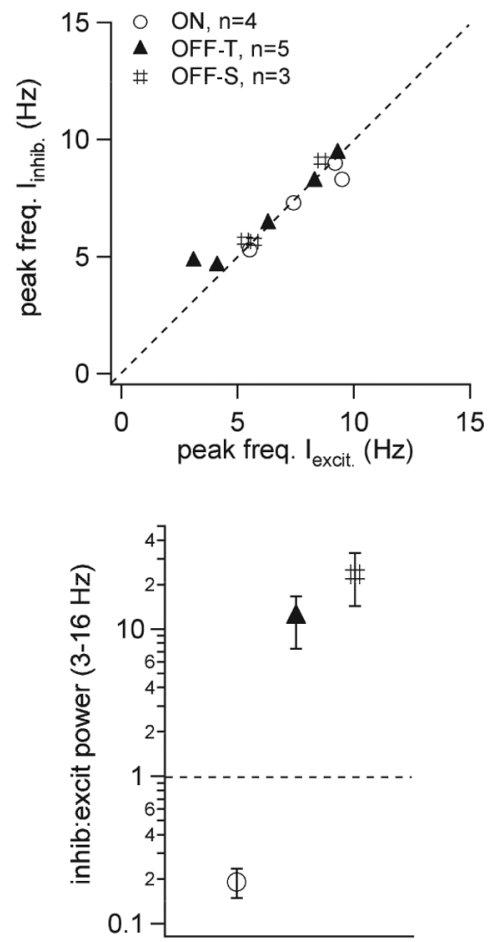

Figure 5. Distinct balance of excitatory and inhibitory synaptic currents in ON and OFF RD RGCs. $A$, Comparison of excitatory $\left(V_{\text {hold }}=-70 \mathrm{mV}\right.$; black, bottom traces) and inhibitory $\left(V_{\text {hold }}=0\right.$ $\mathrm{mV}$; gray, top traces) synaptic currents from individual cells. $\boldsymbol{B}$, Power spectra of excitatory (solid line) and inhibitory (dotted line) currents from the cells in $A$. C, Top, Correlation between frequency of inhibitory and excitatory currents from individual ON, OFF-T, and OFF-S cells $(n=12)$. Frequency measured from power spectra as in Figure 4 . Bottom, Ratio of inhibitory to excitatory power for $\mathrm{ON}, \mathrm{OFF}-\mathrm{T}$, and $\mathrm{OFF}-\mathrm{S}$ cells. Note that the ratio is low for ON cells and high for OFF cells, reflecting a distinct balance of excitatory and inhibitory synaptic currents. Recordings were made with $\mathrm{CsMeS \textrm {O } _ { 4 }}$ internal solution (see Materials and Methods). Error bars indicate SEM.

recordings in both cell types (Fig. $4 B$ ). The strong correlation $(r=0.95 ; p<0.001)$ between the peak frequency of spiking and the peak frequency of currents from all individual cells where both were recorded ( $n=18$ total; 7 ON, 8 OFF-T, 3 OFF-S) is apparent in the plot of Figure $4 C$.

The fluctuating current recorded from voltage-clamped RGCs in RD retina were reduced by $>90 \%$ by exposure to a mixture of synaptic antagonists (in $\mu \mathrm{M}$ ) $50 \mathrm{~L}-\mathrm{APB}, 20$ CNQX, 50 APV, 1 strychnine, and 50 picrotoxin (supplemental Fig. 1, available at www.jneurosci.org as supplemental material). This is additional evidence that the rhythmic currents are generated extrinsically by spontaneous variation in synaptic inputs. The baseline fluctuations in current were still present, however, in the presence of L-APB alone, an mGluR6 agonist, indicating that the source of the persistent synaptic activity that gives rise to the oscillatory activity is downstream of the photoreceptor-to-ON bipolar synapse (supplemental Fig. 1, available at www. jneurosci.org as supplemental material).

\section{Balance of excitation and inhibition in RD RGCs}

Thus far, the experiments have shown that rhythmic synaptic input drives firing in both ON and OFF RGCs in the RD retina. Differences in the amplitude and dynamics of synaptic inputs to $\mathrm{ON}$ and OFF cells are also apparent: at rest $\left(V_{\text {hold }}=-70\right.$ $\mathrm{mV}$ ), there are monophasic inward currents in ON cells and biphasic currents in OFF-T and OFF-S cells. This could reflect a different balance of excitatory (inward) and inhibitory (out- ward) synaptic currents in these cell types, consistent with the different allotment of excitatory and inhibitory synaptic input to ON and OFF cells in WT RGCs (Pang et al., 2003; Murphy and Rieke, 2006) (supplemental Fig. 2, available at www.jneurosci.org as supplemental material). To examine more closely the effect of photoreceptor degeneration on the balance of synaptic inputs to RD RGCs, membrane currents were recorded in voltage clamp from RGCs held at membrane potentials that were close to the reversal potential for excitatory $(0$ $\mathrm{mV}$ ) and inhibitory $(-70 \mathrm{mV})$ synaptic currents (Taylor et al., 2000; Pang et al., 2003; Murphy and Rieke, 2006). Recordings of resting currents in ON and OFF RD RGCs at -70 and $0 \mathrm{mV}$ are shown in Figure $5 A$. In ON cells, large-amplitude rhythmic excitatory currents $\left(V_{\text {hold }}=-70 \mathrm{mV}\right.$ ) were reduced by changing the holding potential to $0 \mathrm{mV}$. In OFF cells, the smallamplitude rhythmic inward currents recorded at $-70 \mathrm{mV}$ were replaced by large-amplitude outward currents at $V_{\text {hold }}=$ $0 \mathrm{mV}$ (Fig. 5A). The difference in the recorded currents at these two holding potentials in these three cell types was quantitated using spectral analysis. It is apparent in the power spectra plotted in Figure $5 B$ that the peak power at the cells beat frequency was largest in currents recorded at $-70 \mathrm{mV}$ in the $\mathrm{ON}$ cell and at $0 \mathrm{mV}$ in the OFF cells. Data pooled from a collection of 12 RGCs in RD retina ( 4 ON, 5 OFF-T, 3 OFF-S) showed that there is a strong correlation $(r=0.96 ; p<0.001)$ between the frequency of peak power of the currents recorded at -70 and $0 \mathrm{mV}$ (Fig. $5 C$, top). These results indicate that 
excitatory and inhibitory inputs are active at the same fundamental frequency in ON and OFF type RD RGCs. The ratio of inhibitory-to-excitatory power in the $\mathrm{ON}$ and OFF cell types is very different, however, with OFF cells receiving $>10$ fold stronger inhibition than $\mathrm{ON}$ cells (Fig. 5C, bottom). This is consistent with previous measurements of the relative weights of inhibitory and excitatory conductances in ON and OFF RGCs in the WT retina (Pang et al., 2003; Murphy and Rieke, 2006) and supports the conclusion that the balance of excitatory and inhibitory inputs to ON and OFF RGCs is mostly conserved in $\mathrm{RD}$ retina.

\section{Similarity of intrinsic firing properties in WT and RD RGCs}

Because the continuous generation of rhythmic synaptic input and spike activity might be expected to provoke compensatory changes in cellular physiology (Gorter et al., 2002; Frick and Johnston, 2005), spike generation and firing properties of WT (Margolis and Detwiler, 2007) and RD RGCs were compared. In the presence of synaptic blockers the intrinsic characteristics of electrically evoked spike activity in ON, OFF-T, and OFF-S RGCs were indistinguishable in $\mathrm{RD}$ and WT retinas (Fig. 6). Both $\mathrm{ON}$ and OFF cells in RD retina showed similar changes in firing frequency with increasing amplitude current injection, as well as similar spike-frequency adaptation and capacity for sustained firing (Fig. $6 \mathrm{~A}$ ). The maximum stimulated firing frequencies were $\sim 300-400 \mathrm{~Hz}$ and not different in RD compared with WT in any cell type (Fig. 6C) (ON: WT, $317 \pm 45$ $\mathrm{Hz}, n=6$; RD, $341 \pm 46 \mathrm{~Hz}, n=3 ; p=$ 0.7; OFF-T: WT, $315 \pm 52 \mathrm{~Hz}, n=5$; RD, $362 \pm 39 \mathrm{~Hz}, n=4 ; p=0.7)$. Action potential durations were submillisecond in all recordings (WT, $n=12 ; \mathrm{RD}, n=$ 14).

Like in WT retina, RD ON RGCs lacked the ability for rebound firing (Fig. 6B), even when driven to very negative voltages $(<-100 \mathrm{mV})$. Consistent with this, afterdepolarization (ADP) amplitude was approximately twofold to fourfold smaller in $\mathrm{ON}(<5 \mathrm{mV})$ than OFF cells $(>10 \mathrm{mV})$. In three RD ON cells, ADP amplitude was smaller than in WT ON cells (WT, $3.7 \pm 0.3 \mathrm{mV}, n=6$; RD, $1.9 \pm$ $0.4 \mathrm{mV}, n=3$; $p<0.05)$.

OFF cells in RD retina showed characteristic WT-like responses to negative current injection. Importantly, they continued to exhibit rebound excitation after a hyperpolarizing potential change (Fig. $6 A$, arrows, $B$ ). This is a distinguishing difference between $\mathrm{ON}$ and OFF RGCs in WT retina (Margolis and Detwiler, 2007) (D. J. Margolis, A. J. Gartland, T. Euler, W. Denk, and P. B. Detwiler, unpublished observation). ADP amplitudes in 5 and 4 , respectively).
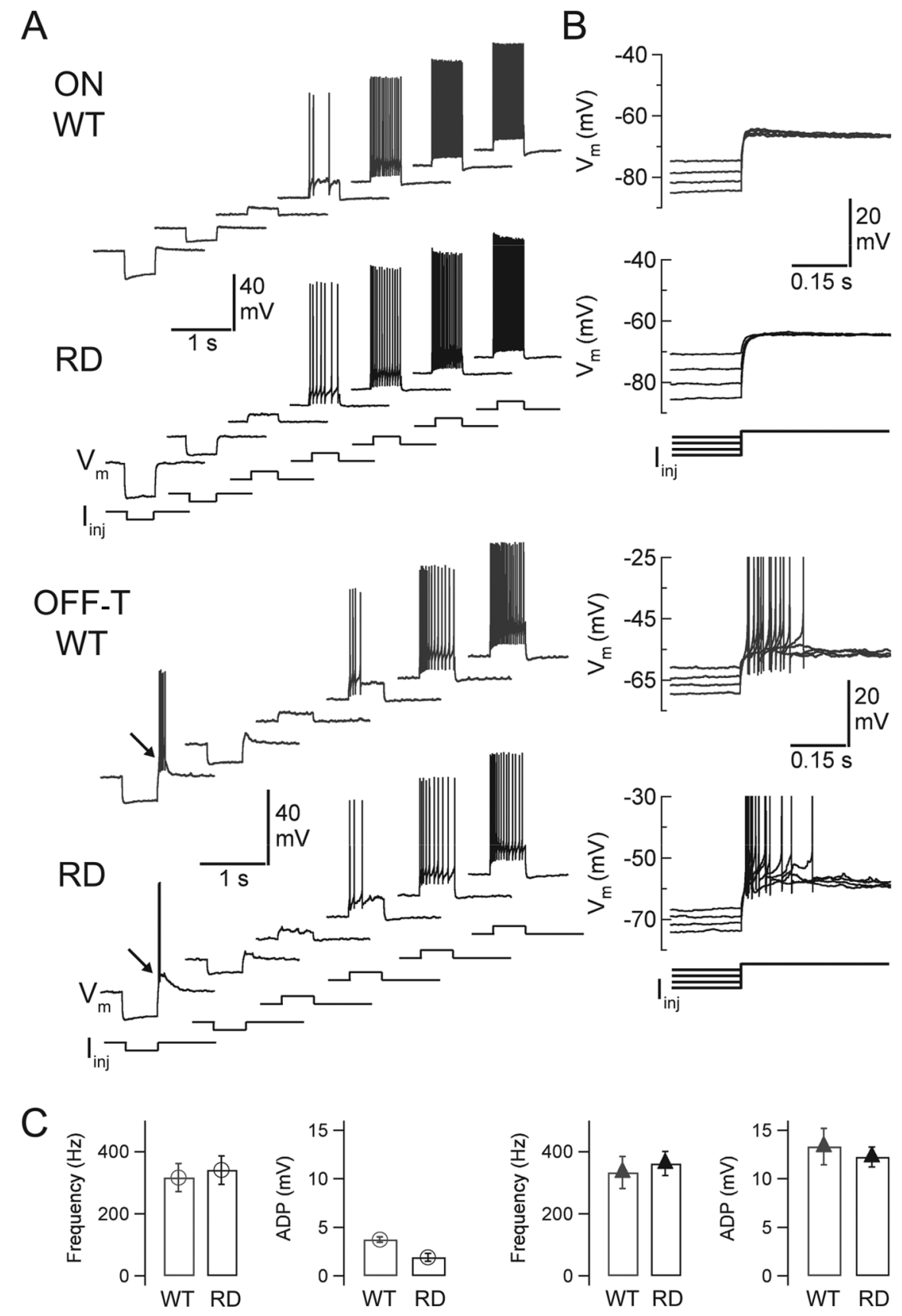

Figure 6. Similarity of intrinsic electrical properties in WT and RD RGCs. $A$, Voltage $\left(V_{m}\right)$ responses to injected current (linj) for ON (top) and OFF-T (bottom) cells recorded in whole-cell current-clamp mode in the presence of synaptic blockers (in $\mu \mathrm{m}$ : 50 L-APB, 20 CNQX, 50 APV , 1 strychnine, and 50 picrotoxin). Arrows indicate presence of rebound firing in both WT and RD OFF-T cells. $\boldsymbol{B}$, Four superimposed responses to negative current injection. The strength of the responses is proportional to the level of hyperpolarization. C, Average maximum firing frequency and ADP strength for ON (left; $n=6$ and 3) and OFF-T cells (right; $n=$

RD OFF-T cells were large and not different from WT (WT, $13.3 \pm 1.9 \mathrm{mV}, n=5 ; \mathrm{RD}, 12.3 \pm 1.0 \mathrm{mV}, n=4 ; p=0.7$ ) (Fig. $6 C)$. Rebound duration and the relationship to the strength of negative current injection were also essentially the same in RD and WT RGCs (Fig. 6B). Three of three RD OFF-S cells also showed WT-like intrinsic properties, including rebound firing (data not shown).

Together, these results indicate that the distinct differences in intrinsic electrophysiological properties of ON and OFF RGCs are still present in $\mathrm{RD}$ retina. RGC intrinsic firing properties are stable despite altered ongoing synaptic input. 


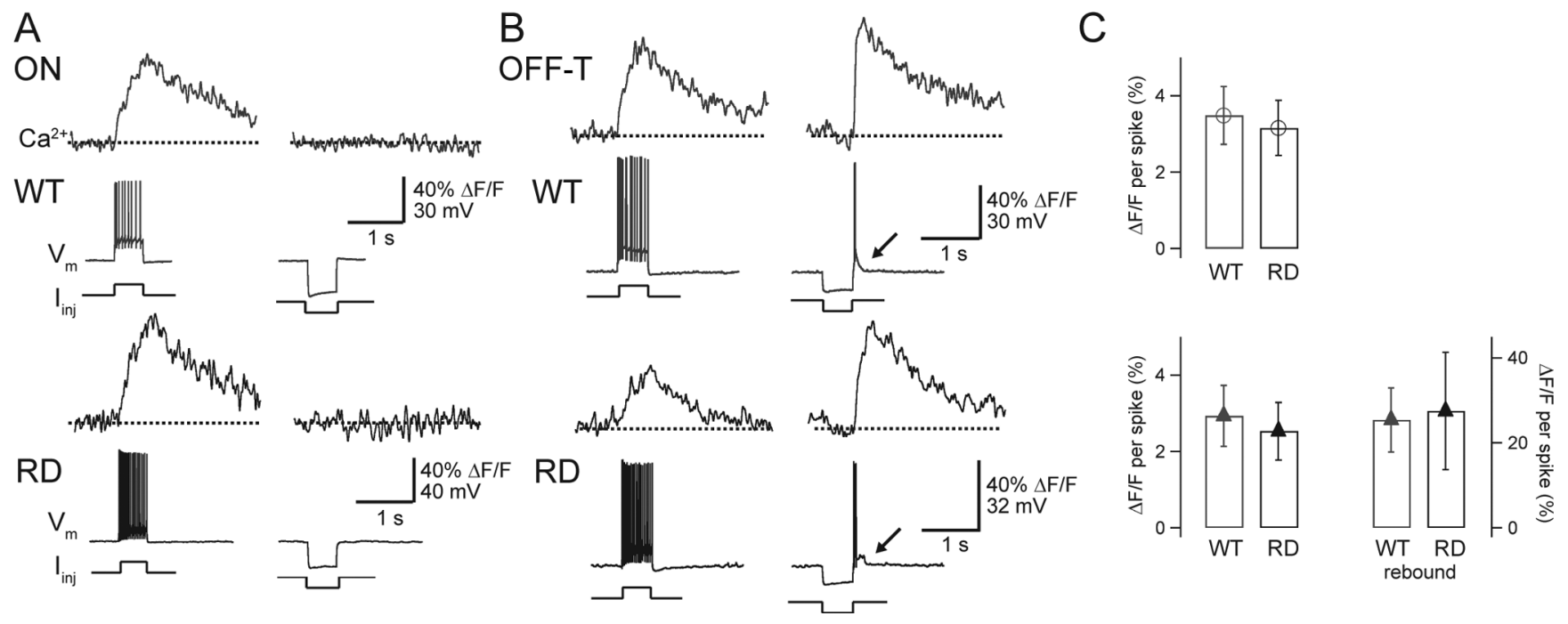

Figure 7. Similarity of spike- and rebound-evoked $\mathrm{Ca}^{2+}$ signals in WT and RD RGCS. $A, \mathrm{Ca}^{2+}$ signals $\left(\mathrm{Ca}^{2+}\right)$ recorded from proximal dendrites during voltage responses $\left(V_{\mathrm{m}}\right)$ to injected current (linj) in ON WT (top) and RD (bottom) RGCS. B, Same as A for OFF-T RGCs. Recordings were made in whole-cell current clamp in the presence of synaptic blockers (in $\mu \mathrm{m:} 50 \mathrm{~L}-\mathrm{APB}, 20 \mathrm{CNQX}, 50 \mathrm{APV}$, 1 strychnine, and 50 picrotoxin). Arrows indicate the presence of rebound firing. $C$, Mean $\mathrm{Ca}^{2+}$ signal amplitude per spike ( $\triangle F / F$ per spike) for ON (top; WT, $n=4 ; \mathrm{RD}, n=3$ ) and $0 \mathrm{FF}-\mathrm{T}$ (bottom; $\mathrm{WT}, n=4[5] ; \mathrm{RD}, n=3) \mathrm{RGCS}$. Note that WT and RD cells display similar $\mathrm{Ca}^{2+}$ signaling profiles for both spiking and rebound firing. Error bars indicate SEM.

\section{Similarity of dendritic $\mathrm{Ca}^{2+}$ signals in WT and RD RGCs}

To test further for changes in the intrinsic properties of RGCs we compared the functional expression of voltage-gated $\mathrm{Ca}^{2+}$ channels in the dendrites of RGCs from WT and RD retina. Changes in $\mathrm{Ca}^{2+}$-dependent fluorescence were measured from line scans across RGC proximal dendrites using two-photon fluorescence microscopy. In both $\mathrm{ON}$ and OFF cells, depolarizing current injection generated spikes and increased intracellular $\mathrm{Ca}^{2+}$ (Fig. $7 A, B)$, resulting from activation of high-voltage-activated $\mathrm{Ca}^{2+}$ channels. Figure 7 also shows that OFF, but not ON, cells have the additional capacity for rebound spike excitation at the termination of a hyperpolarizing voltage step. As shown previously (Margolis and Detwiler, 2007), rebound excitation in OFF cells results from deinactivation of low-voltage-activated (LVA) $\mathrm{Ca}^{2+}$ channels, making them available for activation when the voltage is stepped in the depolarized direction back to the resting potential. The experiments illustrated in Figure $7, A$ and $B$, were repeated on a number of $\mathrm{ON}$ and OFF cells and the results quantified by measuring the relative fluorescence change per spike $(\Delta F / F$ per spike) (see Materials and Methods). The bar graphs in Figure $7 C$ show that there were no significant differences in the fluorescence change per spike in WT versus RD ON and OFF RGCs. In ON cells from WT and RD retina, $\Delta F / F$ s per spike were $3.5 \pm 0.8$ and $3.2 \pm 0.7 \%$, respectively ( $n=4$ and 3 , respectively; $p=0.8$ ) and in OFF cells it was $2.9 \pm 0.8$ and $2.5 \pm 0.8 \%$, respectively $(n=4$ and 3, respectively; $p=0.7$ ). For spikes evoked by rebound firing, $\Delta F / F$ per spike was $25.3 \pm 7.6$ and $27.5 \pm 13.8 \%(n=5$ and $3 ; p=$ 0.9 ) in OFF cells from WT and RD retina, respectively (Fig. 7C). The results of these experiments support the conclusion that photoreceptor degeneration and the associated subsequent changes in retinal physiology do not affect the expression and basic properties of voltage-evoked dendritic $\mathrm{Ca}^{2+}$ signals in either ON or OFF RGCs.

\section{$\mathrm{Ca}^{2+}$ homeostasis during rhythmic activity in RD RGCs}

The resting level of baseline $\mathrm{Ca}^{2+}$ is a trigger of apoptosis and thus plays a well-established role in cell survival. To evaluate the potential influence of baseline $\mathrm{Ca}^{2+}$ on the survival of ganglion cells in retinal degeneration, $\mathrm{Ca}^{2+}$ was measured during resting activity in selected dendrites of RGCs from RD retina. Figure $8 A$ shows two-photon fluorescence images of an ON and OFF RGCs from RD retina. The red boxes mark the proximal dendritic location of line scans $(500 \mathrm{~Hz}$ sampling rate) used to measure the $\mathrm{Ca}^{2+}$-dependent fluorescence signals that are traced in red along with the simultaneously recorded spike activity from each cell. Slow fluctuations in $\mathrm{Ca}^{2+}$ were evident during resting activity in both $\mathrm{ON}$ and $\mathrm{OFF}$ cells. Calcium appeared to rise and fall with changes in spike rate on a time scale of $\sim 1 \mathrm{~s}$. Power spectral analysis showed that resting $\mathrm{Ca}^{2+}$ changes were dominated by low-frequency components ( $n=6$ cells) (data not shown) with insignificant power in the frequency range of the rhythmic spontaneous spike activity $(5-15 \mathrm{~Hz})$. Although obvious $\mathrm{Ca}^{2+}$ changes were not seen with individual bursts of spikes, a correspondence between spiking and $\mathrm{Ca}^{2+}$ was apparent when spike activity was collected over broader bin widths (150 ms) to monitor slower changes in spike rate (Fig. $8 \mathrm{~B}$ ). Changing the spike rate by hyperpolarizing current injection caused a marked reduction in the baseline $\mathrm{Ca}^{2+}$ level in ON but not in OFF cells. This illustrated in the Figure $8 B$ (middle and bottom). In the ON cell, there was a decrease in resting $\mathrm{Ca}^{2+}$ at the onset of the negative current pulse, with the presence of slow, low amplitude $\mathrm{Ca}^{2+}$ fluctuations during the period of increased membrane potential that approximately matched the changes in spike rate. At the termination of the hyperpolarizing step, $\mathrm{Ca}^{2+}$ rapidly retuned to the resting $\mathrm{Ca}^{2+}$ level. Resting $\mathrm{Ca}^{2+}$ signals in OFF cells also tracked changes in spike rate (Fig. $8 B$, right, top), but hyperpolarizing current injection caused a less obvious reduction on the baseline $\mathrm{Ca}^{2+}$ level. Hyperpolarizing the OFF cell did, however, give rise to discrete large amplitude fluctuations in $\mathrm{Ca}^{2+}$ (Fig. 8 B, right, middle, bottom). These increases in $\mathrm{Ca}^{2+}$ were often, but not always, associated with increases in spike activity. When displayed on a faster time base (Fig. $8 C$, right), it was apparent that individual $\mathrm{Ca}^{2+}$ signals were coincident with single spikes as well as with regenerative-like voltage events that were subthreshold for generating full-blown action potentials (Fig. $8 C$, right, arrows).

OFF RGCs are also capable of rebound excitation during resting spike activity, as shown before in the presence of synaptic blockers (Fig. 7). The termination of hyperpolarizing current pulse in OFF, but not ON cells from the RD retina triggered a burst of spikes and a large increase in $\mathrm{Ca}^{2+}$ under resting condi- 
tions (Fig. $8 C$, bottom right). This result and the finding that negative current injection reveals large amplitude discrete $\mathrm{Ca}^{2+}$ fluctuations is consistent with the deinactivation of $\mathrm{LVA} \mathrm{Ca}^{2+}$ channels by hyperpolarization, making them accessible for activation by depolarizing voltage changes, as in WT OFF RGCs. The differences in $\mathrm{Ca}^{2+}$ signaling in $\mathrm{ON}$ and OFF cells suggest that these cell types use distinct mechanisms to regulate $\mathrm{Ca}^{2+}$ at rest. The overall observation that dendritic $\mathrm{Ca}^{2+}$ signals in $\mathrm{RD}$ RGCs are similar to WT, in both ON and OFF cell types, supports the conclusion that expression of voltage-gated $\mathrm{Ca}^{2+}$ channels is stable after photoreceptor degeneration.

\section{Discussion}

Our experiments show that there is ongoing rhythmic spike activity in three identified types of RGCs in the adult RD retina, the classic mouse model of retinal degeneration. Spiking was driven by oscillatory synaptic input from presynaptic circuitry, rather than changes in the intrinsic electrical or $\mathrm{Ca}^{2+}$ signaling properties of RGCs. These findings represent the first detailed electrophysiological measurements from identified types of RGCs in the RD retina, and highlight the functional stability of RGCs during retinal disease. The results have important implications for vision rescue strategies.

\section{Altered firing resulting from aberrant synaptic input}

To evaluate the effect of the absence of photoreceptors on the physiology of selected ganglion cells, the properties $\mathrm{ON}$, OFF-T, and OFF-S RGCs in the WT and $\mathrm{RD}$ mouse retinas were compared. The distinctive rhythmic voltage fluctuations and spike activity present in the RD retina is not present in these cell types in WT retina (Pang et al., 2003; Murphy and Rieke, 2006; Sagdullaev et al., 2006; Margolis and Detwiler, 2007). Nor has this activity been reported under physiological conditions in any other type of adult mammalian RGC. Thus, the periodic spike activity at a characteristic frequency of $\sim 10 \mathrm{~Hz}$ represents a specific form of aberrant activity present during the early stages of retinal degeneration. Two recent reports showing increased glutamate signaling (Marc et al., 2007) and overall spiking activity (Stasheff, 2008) in $\mathrm{RD}$ retina are consistent with this view. We found rhythmic activity in older mice (up to $\mathrm{P} 210$ ), but at a reduced rate. Thus, rhythmic retinal output may be a general feature of retinal degeneration throughout progression of the disease.
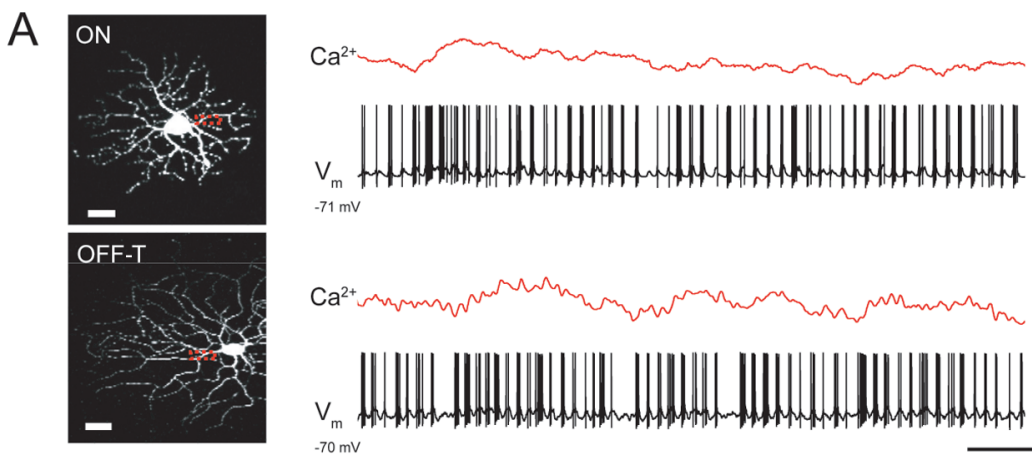

$-71 \mathrm{mv}$
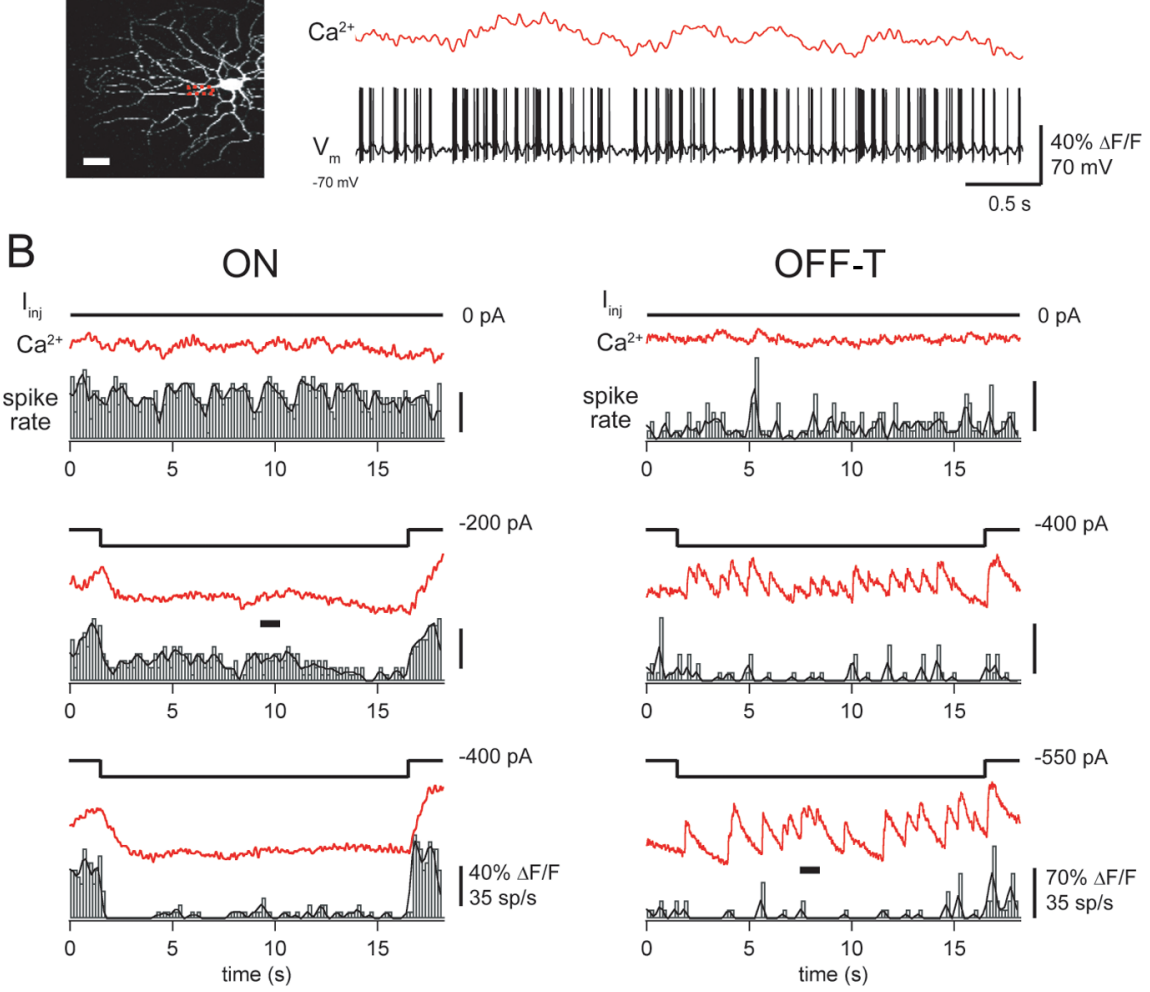

C
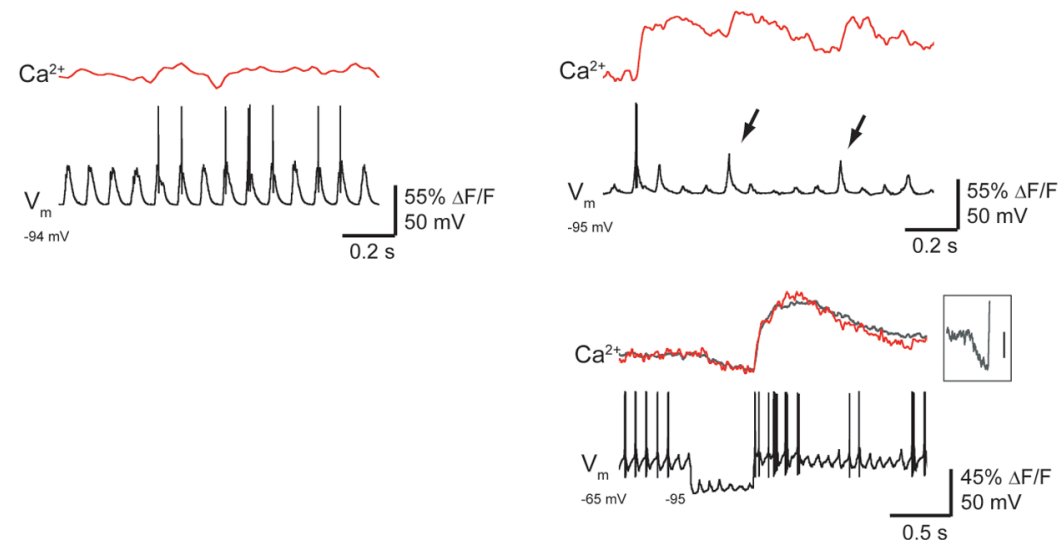

Figure 8. Calcium dynamics during resting activity in RD RGCS. $\boldsymbol{A}$, Simultaneously recorded calcium indicator fluorescence $\left(\mathrm{Ca}^{2+}\right.$, red) and membrane potential $\left(V_{\mathrm{m}}\right.$, black) from cells show at left. Red boxes on proximal dendrites indicate scanned regions. $B, C^{2+}$ signals (red) and spike rate (black; bin width, $150 \mathrm{~ms}$ ) during resting activity [injected current (linj) $=0$ ] from two different cells than in $\boldsymbol{A}$. Note the longer time scale. In the $0 \mathrm{~N}$ cell (left), linj reduced spike rate and resting $\mathrm{Ca}^{2+}$. Baseline membrane potentials for the $0 \mathrm{~N}$ cell at rest (during pulse) were $-71,-70(-94)$, and $-70(-108) \mathrm{mV}$ for top, middle, and bottom panels, respectively. Baseline membrane potentials for the OFF-T cell at rest during pulse were $-70,-70(-87),-70$ $(-95) \mathrm{mV}$ for top, middle, and bottom panels, respectively. C, Blow-ups of regions corresponding to bars in $\boldsymbol{B}$ (middle, $\sim t=9 \mathrm{~s}$ for $0 \mathrm{~N}$ cell; bottom, $\sim t=7 \mathrm{~s}$ for $0 \mathrm{FF}-\mathrm{T}$ cell). Note that both spikes and subthreshold regenerative-like events are associated with $\mathrm{Ca}^{2+}$ signals during hyperpolarization in OFF-T cell (arrows). The bottom right plot shows rebound-evoked $\mathrm{Ca}^{2+}$ signal during resting activity (linj $=-400 \mathrm{pA}$ for $0.5 \mathrm{~s}$ ). The superimposed gray trace is the mean of three responses to $-550,-400$, and $-300 \mathrm{pA}$. The hyperpolarizing portion of the mean response is shown in the inset on the right to emphasize $\mathrm{Ca}^{2+}$ decrease. Scale bars: $\boldsymbol{A}, 25 \mu \mathrm{m} ; \boldsymbol{C}$, inset, $10 \% \Delta \mathrm{F} / \mathrm{F}$. 
The results showed that the rhythmic spike activity was caused by oscillatory synaptic input in both ON, OFF-T, and OFF-S RGCs. This indicates that the loss of photoreceptor input to the retina and/or the synaptic alterations that occur during retinal degeneration result in recurrent episodic release of neurotransmitter across parallel $\mathrm{ON}$ and OFF retinal pathways. Available evidence argues against the possibility that the activity occurs in phase across the full mosaic of RGCs. Electroretinogram recordings from RD mice (Strettoi et al., 2002) and humans (Francis et al., 2005) with retinal dystrophy show no signs of oscillatory potentials, which would be expected to be seen if the entire retina were "beating" synchronously. There is also no sign of synchronous activity in multielectrode recordings from RD mouse retina (Stasheff, 2008), consistent with the rhythmic retinal activity being asynchronous at least on a spatial scale of $>200 \mu \mathrm{m}$, the spacing of the multielectrode array.

It is unclear what effect ongoing RGC spike activity may have on postsynaptic visual targets in the brain, but it is known that the $\mathrm{RD}$ retina retains functional synaptic connections with higher visual centers (Bi et al., 2006; Chen et al., 2006). Thus, it is possible that the persistent retinal activity we have observed in the blind retina is the source of photopsia in patients with retinitis pigmentosa who describe the sensation of seeing random flashes or shimmering lights in the absence of visual stimulation (Lepore, 1990; Amos, 1999; Murtha and Stasheff, 2003).

\section{Maintenance of dendritic structure, firing properties and $\mathrm{Ca}^{2+}$ signaling}

Despite the cellular changes that occur during retinal degeneration (Marc et al., 2003; Jones and Marc, 2005), the dendrites of three identified RGC types retain their characteristic branching and stratification patterns. That morphological changes are known to occur in horizontal and bipolar cells of RD retina (Strettoi and Pignatelli, 2000) and generally in response to altered synaptic input in other cell types (Deitch and Rubel, 1984; Kossut and Juliano, 1999), suggests that RGCs have a remarkable degree of morphological stability. These cells, the output cells of the retina, are also functionally stable. This is supported by the fact that the characteristic differences in the intrinsic electrical properties and dendritic $\mathrm{Ca}^{2+}$ signals between ON and OFF RGCs are the same in WT and RD retinas. Although there is little evidence of plasticity in the adult retina (Xia et al., 2007), it is nevertheless surprising that the irreversible and long term disruption of normal retinal architecture and function has no effect on the fundamental properties of $\mathrm{ON}$ and OFF output cells. The inherent stability of RGCs may be designed to ensure the maintenance of normal retina circuitry during prolonged changes in illumination that occur diurnally. Light, for example, by suppressing transmitter release from photoreceptors deprives the retina of photoreceptor output, which is also a consequence of photoreceptor loss in retinal degeneration.

\section{The function of rhythmic activity: a link between cell survival and $\mathrm{Ca}^{2+}$ homeostasis?}

What is the function of RGC activity after photoreceptor loss? One possibility is that RGCs must be active to survive. Neuronal survival depends on maintaining appropriate intracellular $\mathrm{Ca}^{2+}$ concentration. Because reducing spike activity by direct hyperpolarization changes $\mathrm{Ca}^{2+}$ dynamics in both ON and OFF cells (Fig. 8), it is likely that persistent spike activity plays a role keeping $\mathrm{Ca}^{2+}$ at a level that is compatible with cell survival. It has been proposed that a self-excitatory process plays a role in cell survival during retinal degeneration (Jones and Marc, 2005). The pres- ence of persistent synaptic input at a fixed "resonant" frequency across both ON and OFF retinal pathways, and the majority of randomly sampled RGCs (Stasheff, 2008), is consistent with this proposal. Oscillatory activity may therefore represent an intrinsic retinal mechanism necessary for cell survival, and may be a general strategy for keeping neurons alive in the absence of normal synaptic transmission. This hypothesis could be tested by comparing the survival of RGCs in RD retina in the presence and absence of long-term synaptic blockade using intraocular injection of slow release antagonists.

\section{Strategies for selective stimulation of visual pathways}

Our results have important implications for developing new strategies for restoring vision in blindness caused by retinal degeneration. Several promising approaches involving cell transplantation (MacLaren et al., 2006) as well as direct electrical (Zrenner, 2002; Hetling and Baig-Silva, 2004; Weiland et al., 2005; Fried et al., 2006; Sekirnjak et al., 2006) and optical (Bi et al., 2006; Farah et al., 2007) stimulation of surviving RGCs are currently being pursued. A major impasse is the inability to stimulate different retinal pathways selectively, which is a necessary step for the recovery of normal vision.

OFF, but not ON, cells are capable of rebound excitation, a burst of action potentials at the termination of a hyperpolarizing voltage step (Margolis and Detwiler, 2007). This distinguishing feature between OFF and ON cells is retained in the RD mouse (Figs. 6-8) and may offer a potential target for selective control of ON and OFF retinal outputs. Rebound excitation stimulates OFF but not ON RGCs directly, without engaging the synaptic circuitry. However, rebound requires $\sim 50-500 \mathrm{~ms}$ of hyperpolarization (Lee et al., 2003; Margolis and Detwiler, 2007), which is difficult to achieve via extracellular electrical stimulation (such as that used in epi-retinal prosthetic devices). A combination of new molecular-genetic and optical methods could potentially be used to accomplish this. The bidirectional control of neural activity with different wavelengths of light has been reported recently using the expression of light sensitive ion channels and pumps (Zhang et al., 2007). In these studies, blue light was used to activate channelrhodopsin-2 (ChR2), leading to net cation influx and depolarization, whereas yellow light was used to activate halorhodopsin (NpHR), causing chloride influx and hyperpolarization. Bi et al. (2006) expressed ChR2 in retinas of RD mice, and showed that in the presence of synaptic blockers RGC firing patterns could be controlled with light in precise spatiotemporal patterns. However, ChR2 expression was not confined to particular types of RGCs, effectively changing all RGCs to ON cells; furthermore, expression of NpHR was not attempted. One possibility is that NpHR expression could be used to drive rebound firing in OFF RGCs. This approach could provide a way to selectively control different retinal pathways, and would represent a significant step toward development of a prosthetic device that mimics natural vision.

\section{References}

Amos JF (1999) Differential diagnosis of common etiologies of photopsia. J Am Optom Assoc 70:485-504.

Bi A, Cui J, Ma YP, Olshevskaya E, Pu M, Dizhoor AM, Pan ZH (2006) Ectopic expression of a microbial-type rhodopsin restores visual responses in mice with photoreceptor degeneration. Neuron 50:23-33.

Blanks JC, Adinolfi AM, Lolley RN (1974) Photoreceptor degeneration and synaptogenesis in retinal-degenerative (rd) mice. J Comp Neurol 156:95-106.

Carter-Dawson LD, LaVail MM, Sidman RL (1978) Differential effect of the rd mutation on rods and cones in the mouse retina. Invest Ophthalmol Vis Sci 17:489-498. 
Chen SJ, Mahadevappa M, Roizenblatt R, Weiland J, Humayun M (2006) Neural responses elicited by electrical stimulation of the retina. Trans Am Ophthalmol Soc 104:252-259.

Daiger SP, Bowne SJ, Sullivan LS (2007) Perspective on genes and mutations causing retinitis pigmentosa. Arch Ophthalmol 125:151-158.

Deitch JS, Rubel EW (1984) Afferent influences on brain stem auditory nuclei of the chicken: time course and specificity of dendritic atrophy following deafferentation. J Comp Neurol 229:66-79.

Denk W, Strickler JH, Webb WW (1990) Two-photon laser scanning fluorescence microscopy. Science 248:73-76.

Euler T, Detwiler PB, Denk W (2002) Directionally selective calcium signals in dendrites of starburst amacrine cells. Nature 418:845-852.

Farah N, Reutsky I, Shoham S (2007) Patterned optical activation of retinal ganglion cells. Conf Proc IEEE Eng Med Biol Soc 1:6368-6370.

Farber DB, Flannery JG, Bowes-Rickman C (1994) The rd mouse story: seventy years of research on an animal model of inherited retinal degeneration. Prog Retin Eye Res 13:13-64.

Field GD, Chichilnisky EJ (2007) Information processing in the primate retina: circuitry and coding. Annu Rev Neurosci 30:1-30.

Francis PJ, Marinescu A, Fitzke FW, Bird AC, Holder GE (2005) Acute zonal occult outer retinopathy: towards a set of diagnostic criteria. Br J Ophthalmol 89:70-73.

Frick A, Johnston D (2005) Plasticity of dendritic excitability. J Neurobiol 64:100-115.

Fried SI, Hsueh HA, Werblin FS (2006) A method for generating precise temporal patterns of retinal spiking using prosthetic stimulation. J Neurophysiol 95:970-978.

Gorter JA, Borgdorff AJ, van Vliet EA, Lopes da Silva FH, Wadman WJ (2002) Differential and long-lasting alterations of high-voltage activated calcium currents in CA1 and dentate granule neurons after status epilepticus. Eur J Neurosci 16:701-712.

Hetling JR, Baig-Silva MS (2004) Neural prostheses for vision: designing a functional interface with retinal neurons. Neurol Res 26:21-34.

Jimenez AJ, Garcia-Fernandez JM, Gonzalez B, Foster RG (1996) The spatio-temporal pattern of photoreceptor degeneration in the aged $\mathrm{rd} / \mathrm{rd}$ mouse retina. Cell Tissue Res 284:193-202.

Jones BW, Marc RE (2005) Retinal remodeling during retinal degeneration. Exp Eye Res 81:123-137.

Jones BW, Watt CB, Frederick JM, Baehr W, Chen CK, Levine EM, Milam AH, Lavail MM, Marc RE (2003) Retinal remodeling triggered by photoreceptor degenerations. J Comp Neurol 464:1-16.

Jones BW, Watt CB, Marc RE (2005) Retinal remodelling. Clin Exp Optom 88:282-291.

Kossut M, Juliano SL (1999) Anatomical correlates of representational map reorganization induced by partial vibrissectomy in the barrel cortex of adult mice. Neuroscience 92:807-817.

Lee SC, Hayashida Y, Ishida AT (2003) Availability of low-threshold $\mathrm{Ca}^{2+}$ current in retinal ganglion cells. J Neurophysiol 90:3888-3901.

Lepore FE (1990) Spontaneous visual phenomena with visual loss: 104 patients with lesions of retinal and neural afferent pathways. Neurology 40:444-447.

MacLaren RE, Pearson RA, MacNeil A, Douglas RH, Salt TE, Akimoto M, Swaroop A, Sowden JC, Ali RR (2006) Retinal repair by transplantation of photoreceptor precursors. Nature 444:203-207.

Marc RE, Jones BW (2003) Retinal remodeling in inherited photoreceptor degenerations. Mol Neurobiol 28:139-147.
Marc RE, Jones BW, Watt CB, Strettoi E (2003) Neural remodeling in retinal degeneration. Prog Retin Eye Res 22:607-655.

Marc RE, Jones BW, Anderson JR, Kinard K, Marshak DW, Wilson JH, Wensel T, Lucas RJ (2007) Neural reprogramming in retinal degeneration. Invest Ophthalmol Vis Sci 48:3364-3371.

Margolis DJ, Detwiler PB (2007) Different mechanisms generate maintained activity in $\mathrm{ON}$ and $\mathrm{OFF}$ retinal ganglion cells. J Neurosci 27:5994-6005

Masland RH (2001) The fundamental plan of the retina. Nat Neurosci 4:877-886.

Murphy GJ, Rieke F (2006) Network variability limits stimulus-evoked spike timing precision in retinal ganglion cells. Neuron 52:511-524.

Murtha T, Stasheff SF (2003) Visual dysfunction in retinal and optic nerve disease. Neurol Clin 21:445-481.

Nelson R, Famiglietti Jr EV, Kolb H (1978) Intracellular staining reveals different levels of stratification for on- and off-center ganglion cells in cat retina. J Neurophysiol 41:472-483.

Pang JJ, Gao F, Wu SM (2003) Light-evoked excitatory and inhibitory synaptic inputs to ON and OFF alpha ganglion cells in the mouse retina. J Neurosci 23:6063-6073.

Phelan JK, Bok D (2000) A brief review of retinitis pigmentosa and the identified retinitis pigmentosa genes. Mol Vis 6:116-124.

Punzo C, Cepko C (2007) Cellular responses to photoreceptor death in the rd1 mouse model of retinal degeneration. Invest Ophthalmol Vis Sci 48:849-857.

Sagdullaev BT, McCall MA, Lukasiewicz PD (2006) Presynaptic inhibition modulates spillover, creating distinct dynamic response ranges of sensory output. Neuron 50:923-935.

Schiller PH (1992) The ON and OFF channels of the visual system. Trends Neurosci 15:86-92.

Sekirnjak C, Hottowy P, Sher A, Dabrowski W, Litke AM, Chichilnisky EJ (2006) Electrical stimulation of mammalian retinal ganglion cells with multielectrode arrays. J Neurophysiol 95:3311-3327.

Stasheff SF (2008) Emergence of sustained spontaneous hyperactivity and temporary preservation of OFF responses in ganglion cells of the retinal degeneration (rd1) mouse. J Neurophysiol 99:1408-1421.

Strettoi E, Pignatelli V (2000) Modifications of retinal neurons in a mouse model of retinitis pigmentosa. Proc Natl Acad Sci USA 97:11020-11025.

Strettoi E, Porciatti V, Falsini B, Pignatelli V, Rossi C (2002) Morphological and functional abnormalities in the inner retina of the $\mathrm{rd} / \mathrm{rd}$ mouse. J Neurosci 22:5492-5504.

Taylor WR, He S, Levick WR, Vaney DI (2000) Dendritic computation of direction selectivity by retinal ganglion cells. Science 289:2347-2350.

Wassle H (2004) Parallel processing in the mammalian retina. Nat Rev Neurosci 5:747-757.

Weiland JD, Liu W, Humayun MS (2005) Retinal prosthesis. Annu Rev Biomed Eng 7:361-401.

Xia Y, Nawy S, Carroll RC (2007) Activity-dependent synaptic plasticity in retinal ganglion cells. J Neurosci 27:12221-12229.

Zhang F, Wang LP, Brauner M, Liewald JF, Kay K, Watzke N, Wood PG, Bamberg E, Nagel G, Gottschalk A, Deisseroth K (2007) Multimodal fast optical interrogation of neural circuitry. Nature 446:633-639.

Zrenner E (2002) Will retinal implants restore vision? Science 295:10221025 